\title{
Metalwork Removal In Potential Army Recruits. Evidence- Based Changes To Entry Criteria
}

\author{
M Townend, P Parker
}

Current Army entry criteria published in the Joint Service Publication 346 (JSP 346, app. A-11, para 04056-65) demands that all army applicants should have any orthopaedic metalwork removed, bar single asymptomatic screws, and then wait a further 6 months prior to attempting entry. This assumes the individual remains functionally normal. The Army Training and Recruiting Agency (ATRA) receive frequent queries from civilian orthopaedic surgeons as to the validity of these procedures. Many claim that they are unnecessary and put the patient at risk of developing serious permanent complications, and that there is no basis in the orthopaedic literature for this ruling (1).

ATRA receives 32,000 enquiries and 28,000 formal applications yearly. This is more than the Royal Air Force and the Royal Navy put together. 25\% of these applications fail to meet accepted medical entry criteria for a variety of reasons, mainly musculoskeletal disorders and asthma (2). The final total Army intake in 2003-4 was in fact 13,783. Relaxation of some entrance standards could help to improve recruitment, without increasing risk to individuals.

Metalwork removal is a common procedure. Table 1 shows a list of common clinical indications for removal. Pain is often cited as an indication for removal, however following metalwork removal, pain persists in almost $50 \%$ of cases. This casts doubt on the validity of pain itself as an indicator for removal (3). A Norwegian study found that $15 \%$ of elective theatre time was used to remove metalwork. This equated to $29 \%$ of all elective cases over a seven-year period. These potentially unnecessary procedures pose a significant financial and resource drain on the medical system (4).

Table 1. Indications for Metalwork Removal.

Capt M Townend MB

ChB RAMC

Lt Col P Parker

FRCSEd (Orth)

RAMC

Orthopaedic

Department,

MDHU (N),

Friarage Hospital,

Northallerton,

DL6 1JG following removal of asymptomatic metalwork. The average rate was $20 \%$ for both major and minor complications.
Forearm plate removal carried the highest complication rate - $40 \%$ (5). A separate review in 1996 found refracture rates of between $0 \%$ and $20 \%$ depending on the type of plate used, with narrow large fragment plates being the worst (6). Specific studies looking at tibial and femoral intramedullary nail removal have also demonstrated a refracture rate of $6.5 \%$ and hence cautioned against 'routine' removal (7). As many of these complications will be permanent, it seems surprising that it is often less experienced junior surgeons, with higher complication rates, who are left to conduct these procedures (5). There are also considerable medico-legal implications in demanding that individuals undergo potentially hazardous surgery, especially when there are no guarantees that they would be accepted for entry afterwards. Equally, recruits sustaining metalwork related injuries during training could have grounds for redress if allowed entry.

Table 2. Metalwork Removal Complication Rates.

- Brown et al, J R Coll Edin (8) 19\%

Kahle et al, J Pediatr Orthop (9) 13\%

- Richards et al, Injury (10)

- Langkamer et al, JBJS (11)

$3 \%$

- Bednar et al, Can J Surg (12) $40 \%$

Chia et al, Singapore Med J (13) 27\%

\section{The Military Scenario}

There is some debate in the literature as to the exact effects retained metalwork has on surrounding tissue. Plate osteopenia and stress shielding cause weakness of local bone and the metalwork itself can act as a stress riser. Open screw holes have been found to reduce rotational strength and energy absorbing capacity by up to $50 \%$ in clinical tests $(14,15)$ : Metalwork removal itself could then be causative of injury, especially when combined with injuries such as stress fractures.

It is widely accepted that military training places considerable physiological stress upon the new civilian recruit. Injuries are commonplace in training establishments, requiring a dedicated medical team to treat them. Most recruits continue training with minimal treatment only, but some require lengthy rehabilitation or, in the worse cases, are medically discharged if the prognosis is poor. At the Infantry Training Centre in Catterick, a recruit has only a $75 \%$ chance of 
making it through basic infantry training first time without injury. The figure is even lower at $47 \%$ if they are volunteers attempting to join the Parachute Regiment.

Stress fractures occur in around 14 in 1,000 recruits and it is known that females are particularly prone (2). The rigorous training recruits undertake is known to cause changes in bone density and metabolism. There is often an osteoblastic/osteoclastic imbalance in the first few weeks of training. Evidence from ATRA suggests females suffer 8 times the risk of developing orthopaedic related injuries, especially stress fractures (2).

It was once apparently reasoned that allowing individuals with retained metalwork into training posed an unacceptable risk and would result in higher levels of injury. This apocryphal theory dates possibly from an era when recruiting was fruitful and the army could afford to turn all but the strongest candidates away.

\section{Retained Metalwork and the Soldier Athlete}

There is no published data looking directly at the military or recruit scenario but similar evidence is available in athletes, albeit in small numbers. Fifteen Welsh professional rugby players with fractures that required internal fixation were observed over 6 years and of these individuals 13 returned to competitive sport without needing any of their metalwork removed. The remaining two suffered minor complications after return to sport. The first complained of painful patellar wires and the second suffered a peri-implant fracture. Both these players returned to full sporting activity following treatment (16).

In a study of 22 non/mal-united clavicle fractures, internal fixation was necessary for the athletes to return to competitive sport (and with a policy of plate non-removal). There were no problems with the retained metalwork reported in the follow up period (17). A small study of 14 patients after forearm plating showed that retained forearm plates could be well tolerated, did not affect bone mineral density nor forearm grip strength, and enabled subsequent normal function (18).

In correspondence with the US Army Rangers, the Norwegian Parachute Ranger Commandos and Airborne Units of the British Army, no significant problems were reported in soldiers with retained metalwork $(14,19,20)$. Soldiers continued to parachute, often under harsh military conditions. No unnatural injuries or abnormal injury rates were reported. It would seem that even with the hazards of military parachuting, retained metalwork is safe. The US Navy has a more rational approach to applicants with retained metalwork and approaches each case individually. According to the recruitment websites of UK civilian organizations such as the Police and the Fire Brigade, routine removal of retained hardware is not specified as an automatic contraindication to service. Applications are considered regardless of the presence of any retained hardware.

Evidence is also available from those existing military personnel who undergo fixation whilst already serving. Many continue their careers without needing intervention and rarely experience problems. Each case is considered on an individual basis by a service orthopaedic consultant advisor. Many retain the metalwork without incident and go on to pursue normal military careers. Below are examples of individuals who have retained metalwork and have successfully entered and passed basic military training (Figures 1 and 2).

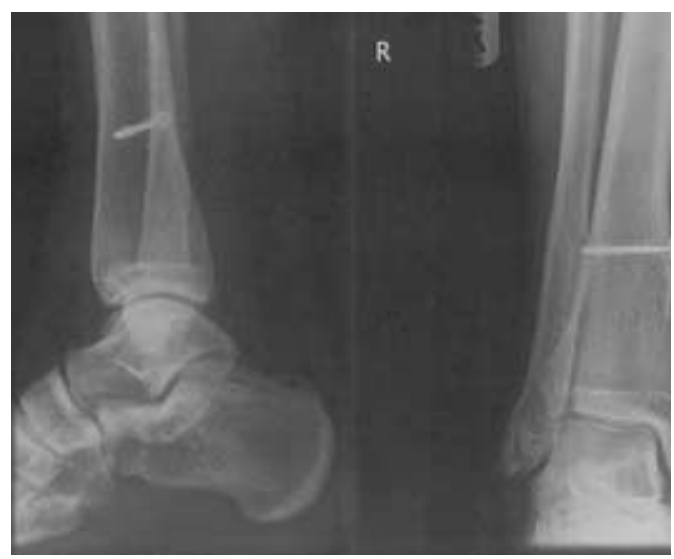

Fig 1. Retained syndesmotic screw in an asymptomatic 16 year old recruit which has migrated proximally with age.

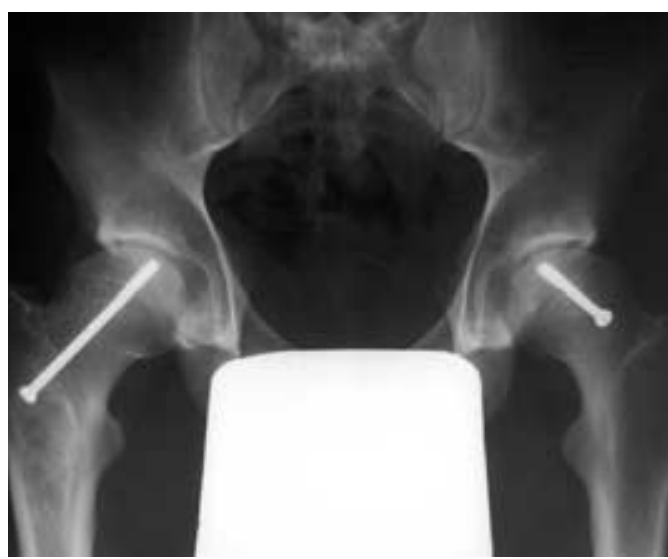

Fig 2. Retained fixation metalwork in a 27 year old soldier who suffered slipped epiphyses during childhood. Removing this electively would be unnecessary, complex and difficult.

Serving personnel undergoing internal fixation of fractures are not expected to have this removed unless the metalwork itself is symptomatic. This is in keeping with current civilian practice. Why then should asymptomatic civilian applicants be managed differently? In light of this study, ATRA, the Recruit Selection Centres, and the Single Service Consultant Advisers are rewriting JSP 346 stating, "Asymptomatic metalwork should not be routinely removed". This new cohort of entrants is also being closely followed. 


\section{Summary}

Civilian practice and the literature do not support the routine removal of metalwork from the asymptomatic patient. A significant risk of complication exists. The MoD and Army Medical Services are expected to conduct themselves in line with current National Health Service guidelines and standards of care. The literature is clear that removal is not indicated unless sound clinical reasons exist. There is no comparable group to that of the recruit with retained metal, but evidence suggests that the rigors of basic training can be accepted without risk to the individual. If a problem arose then removal could be indicated at that time. No studies or papers in support of this policy were found. No evidence was found to support the current British Army policy, which is now being altered.

\section{References}

1. Letter from Mr RM Davies to ATRA 29 Oct 1999.

2. Letter from ATRA, 15 Sept 2000.

3. Brown OL et al. Incidence of hardware-related pain and its effects on functional outcomes after open reduction and internal fixation of ankle fractures. $\mathcal{F}$ Orthop Trauma 2001 May;15(4):271-4.

4. Bostman O, Pihlajamaki H. Routine implant removal after fracture surgery: a potentially reducible consumer of hospital resources in trauma units. F Trauma. 1996 Nov;41(5):846-9.
5. Sanderson PL et al. Complications of metalwork removal. Injury. 1992;23(1):29-30.

6. Beaupre GS, Csongradi JJ. Refracture risk after plate removal in the forearm. F Orthop Trauma. 1996;10(2):87-92.

7. Heffernan et al. Femoral and tibial intramedullary nail removal. Ir $\mathcal{F}$ of Orthop and Tr, 1999, 4(2).

8. Brown RM et al. Removal of metal implants after fracture surgery-indications and complications. $\mathcal{F} R$ Coll Surg Edinb. 1993 Apr;38(2):96-100.

9. Kahle WK. The case against routine metal removal. f Pediatric Orthop. 1994 Mar-Apr;14(2):229-37.

10. Richards RH et al. Observations on removal of metal implants. Injury 1992;23(1):25-8.

11. Langkamer VG, Ackroyd CE. Removal of forearm plates. A review of the complications. $F B F S(\mathrm{Br})$ 1990 Jul;72(4):601-4.

12. Bednar DA, Grandwilewski W. Complications of forearm-plate removal. Can $\mathcal{F}$ Surg. 1993 Feb;36(1):16.

13. Chia J et al. Complications following metal removal: a follow-up of surgically treated forearm fractures. Singapore Med F. 1996 Jun;37(3):268-9.

14. Letter from Prof Arne Ekeland, 12 Sept 2000.

15. Rosson $\mathrm{J}$ et al. Bone weakness after the removal of plates and screws. FBFS Br, 1991 Mar. 73(2):283-6.

16. Evans NA, Evans RO. Playing with metal: fracture implants and contact sport. Br $\mathcal{F}$ Sports Med, 1997; 31(4):319-321.

17. Wentz et al. Reconstruction plate fixation with bone graft for mid-shaft clavicular non-union in semiprofessional athletes. F Orthop Sci. 1999;4(4):269-72.

18. Lindsey RW et al. Effects of retained diaphyseal plates on forearm bone density and grip strength. $\mathcal{F}$ Orthop Trauma 1994 Dec;8(6):462-7.

19. Letter from Col Stephen Craig, 8 Nov 2000.

20. Letter from Lt Col Bricknell, 7 Sept 2000. 